\title{
Professional nurses' perception of the implementation of quality circle programme in a public hospital in the Eastern Cape province
}

\author{
MM Mbovane, MA Cur (student), \\ Department of Health Studies, University of South Africa
}

TR Mavundla, PhD

Professor and Research Coordinator, Department of Health Studies, University of South Africa

JH Roos, D. Litt. Et. Phil,

Senior Lecturer, Department of Health Studies, University of South Africa

\section{Keywords:}

Eastern Cape Province; evaluation; guidelines for the implementation of quality circle; nursing division; professional nurses; public hospital; qualitative research; quality circle; quality improvement

\section{Correspondence address:}

Prof TR Mavundla

Department of Health Studies

PO Box 392

Unisa, 0003

Tel.: (012)429-6769

Fax: (012) 429-6688

E-mail : mavuntr@unisa.ac.za

\section{Abstract: Curationis 30(1): 62-70}

A qualitative rescarch design that is explorative, descriptive and contextual in nature was employed in order to understand and describe the professional nurses' perception of the implementation of a quality circle programme in a public hospital in the Eastern Cape Province. The data-collection techniques were individual semi-structured interviews and field notes. The sample was drawn from a population of 425 Xhosaspeaking professional nurses employed in this institution. The sample comprised eight (8) professional nurses all of whom volunteered for in-depth individual semistructured interviews. All the respondents answered one question: How do you perceive the implementation of the quality circle programme in your hospital?

During data collection and analysis only one theme emerged, namely the perception of quality circle as a forum for discussing patient care problems and future plans. There were four broad categories in this theme, namely

- Staff empowernent

- Teambuilding in the nursing discipline

- Maintenance of standards by nurses

- Challenges to the momentum of a quality circle programme

It is recommended that all three tiers of nursing management be involved in the quality circle programme to improve interpersonal, interdepartmental and intradepartmental communication and concomitantly the nursing care.

\section{Background to the study}

Collins English Dictionary (1991:1268) defines quality as "a distinguishing characteristic, property, or attribute; the basic character or nature of something; ... degree or standard of excellence, esp. a high standard". Gillies (1997:2) describes quality as the features and characteristics of a product or service that bear on its ability to satisfy customers' specified or implied needs. According to Muller (2000:63), quality exists within products or services in varying degrees and can be measured qualitatively or quantitatively.

Donabedian (1980:3) states that with regard to health care and administration, defining and measuring quality is about judging whether and to what extent a specified instance of medical care has 
this property. Nzanira (2002:11) points out that quality can be measured by the providers and the customers.

Quality is multi-dimensional, multifaceted and comprehensive, and may mean different things to different people; hence it is crucial that providers of services should consult the customers to understand their expectations and perceived needs better (Muller 2000:64). Muller (2000:63) identifies the dimensions of quality as accessibility of services, equity, acceptability, efficiency, effectiveness, appropriateness, applicability, safety, amenities, continuity of care, and interpersonal relations. Muller emphasises that these dimensions of quality are crucial and should be considered when assessing the quality of health services.

In this study, the researcher adopted a problem-oriented approach to quality improvement.The researcher introduced a quality circle programme in the nursing division of an Eastern Cape public hospital. Six quality circles emerged: one internal medicine, two surgical, one paediatric, one psychiatric, and one women's health.

Snow and Orlikoff ( 1984:2) define a quality circle as a group of between four and fifteen employees, who work in the same or similar area of an organization and who meet voluntarily on a regular basis to identify, assess and solve problems in their area of work. In this study, a quality circle refers to all categories of nurses, namely:- professional nurses (PNs), enrolled nurses (ENs), and enrolled nursing assistants (ENAs) providing clinical assessment (outpatient care) and bedside nursing care (ward) in the same clinical area. Each group meets voluntarily and ranges between 4 and 15 in number.

Ovretveit, Bate, Cleary, Cretin, Gustafson, McInnes, McLeod, Molfenter, Plsek, Robert, Shortell and Wilson (2002:345351 ) found that quality improvement in health care is achieved rapidly by using quality improvement collaboratives and teams. MacPhee (2002:450-454) identifies the critical components of quality improvement as scientific method, employee participation, teamwork, accountable leadership, appropriate training and on-going education, and client focus.

Weeks (2002:55-64) states that for quality improvement projects to be implemented successfully in health care, health care organisations need to understand and adapt to the financial environments in which they operate. This means that health care organisations need an implementation strategy that is inexpensive and in keeping with their financial environment. In the researcher's view, a quality circle programme fulfils this requirement.

Johnsson, Carlsson and Lagerstrom (2002:850-865) evaluated the training in patient handling and moving skills among hospital and home care personnel according to the Stockholm training concept. The training programme consisted of two models of learning: traditional groups and quality circle. The results indicated that the training in patient handling and moving skills led to improved work technique. The participants improved their transfer technique and experienced less discomfort during the transfer, and patients experienced greater comfort and safety when being transferred. The researcher formulated the research problem from the above background in the following manner.

\section{Problem statement}

Quality circles originated in Japan in the late 1940s to educate and train workers and first line supervisors in the techniques of quality control (Snow \& Orlikoff 1984:4). The United States of America (USA) adopted and introduced quality circles in the health industry and by 1982 at least 200 American hospitals had implemented the programme. In South Africa, however, the quality circle programme is still a new and informal concept. Accordingly, the researcher initiated and facilitated a quality circle programme in a public hospital of the Eastern Cape Province. In order to yield valuable information to expedite the expansion of quality circles in South Africa, the researcher formulated a research question to guide the study. This study is intended to answer the following question.

\section{Research question}

How do professional nurses perceive the implementation of a quality circle programme in a public hospital in the Eastern Cape Province?

\section{Research purpose}

The main purpose of this study was to explore and describe professional nurses' perception of the implementation of quality circle programme in a public hospital in the Eastern Cape Province.

\section{The role of theory in the study}

The researcher reflected the findings of this study within the categories of Donabedian's (1980) model (in Bowling 2002:9), which assesses health services on the basis of structure/input, process, and outcome of services. In this study, the professional nurses who were members of the quality circles constituted the structure/input, and the process was the implementation of a quality circles programme. The impact of the implementation of the quality circle programme was not within the scope of this study because the baseline scores were not identified prior to the implementation process. This study only examined how the professional nurses perceive the implementation of the quality circle programme. The theme, categories and subcategories that emerged supported Donabedian's model because all the categories were processes, namely staff empowerment, teambuilding in nursing and maintenance of nursing standards.

\section{Definitions of concepts}

The following concepts are used in the context of this study as indicated below:

Quality: Gillies (1997:2) defines quality as the totality of features and characteristics of a product or service that bear on its ability to satisfy the specified or implied needs.

Continuous quality improvement: Continuous quality improvement is a systematic, structured organisational process involving personnel planning and executing a continuous flow of improvements to provide health care that meets and exceeds customers' requirements (McLaughlin \& Kaluzny 1999:3).

Professional nurse: Any person entered in the South African Nursing Council registers who has obtained a diploma in general nursing science and arts, or equivalent. This person is a leader of the nursing practice.

Quality Circle: Snow and Orlikoff (1984:2) define a quality circle as a group 
of between four and fifteen employees, who work in the same or similar area of an organization and who meet voluntarily on a regular basis to identify, assess and solve problems in their area of work.

Perception: Those subjective experiences of objects or events that ordinarily result from stimulation of the receptor organs of the body. (Science and Technology Encyclopedia).

Public Hospital: means premises in which patients are received and lodged for the purpose of hospital treatment (Common Wealth Consolidated Acts). In this research this term further refers to a government funded hospital in which this study was undertaken.

\section{Research design and methods}

A research design guides the researcher in planning and implementing the study in a way that is most likely to achieve the intended goal (Burns \& Grove 1997:225). In this study, the researcher used an explorative, descriptive and contextual qualitative research design.

\section{Population}

According to Polit \& Hungler (1995:230) and Wilson (1989:150) it is important, when identifying a population, to be specific about the criteria for inclusion in the population. The sampling criteria for this study were:

- they could be male or female, as the findings would be understood with reference to both sexes;

- $\quad$ they had to be professional nurses

- the ability to speak Xhosa or English was a strong recommendation

- had a working experience of at least two years at this public hospital was required as this period guarantecd that the participants were acquainted with a quality circle programme. they had to have served in a quality circle in their clinical area they had to have one week's induction in quality circle management

- they had to give permission for the interviews to be taperecorded and field notes to be taken

\section{Sampling Technique}

For the purpose of this research, a purposive or judgemental (that is, nonprobability) sampling was used. The technique involves non-random sampling of informants that leads to nonrepresentative sampling of the population (Wilson 1989: 261). This sampling technique was chosen because it offered the researchers participants who had knowledge of quality circle programme in this public hospital.

In this study, the number of participants interviewed was not important, but the researcher collected data until saturated. The sample was drawn from a population of 425 professional nurses working in a public hospital of the Eastern Cape Province. The sample comprised eight professional nurses who volunteered for in-depth individual semi-structured interviews. According to Morse (1995:147), saturation of data is reflected by repeated themes with no new themes emerging. Although data saturation was reached in the fourth interview, the researcher continued with all the interviews and no new themes emerged.

\section{Data Gathering}

Data was gathered using two techniques: in-depth individual semi-structured interviews and observation in the form of field notes. These methods are described briefly below:

\section{- In-depth individual semi- structured interview}

Semi-structured interviews were used to collect data. According to Burns and Grove (1997:353), an interview involves verbal communication between the researcher and the respondent during which information is provided to the researcher.

The in-depth individual semi-structured interview encourages participants to converse freely about the research question(s). The researcher focused on issues of importance to the research question (Polit \& Hungler 1995: 272; Rose 1994: 24; Wilson 1989: 437). According to Rose (1994:24) semistructured interviews could yield valuable data if decisions are taken on who conducts the interview, where they should take place, and how information should be recorded, stored and analyzed. In this study, the researcher conducted in-depth semi-structured individual interviews with professional nurses who met the eligibility criteria. After initial contact with professional nurses selected according to the sampling criteria chosen for this research, informed consent was obtained to use a tape recorder. Date, time and place of interview were confirmed.

The interviews were conducted in a quiet place and the participants were made comfortable for the duration of the interview session. A tape recorder was used to capture the dialogue between the interviewer and the interviewee. The following question was posed to all the intervicwees: "How do you experience the implementation of the quality circle programme in this hospital?" Facilitative communication skills were employed to encourage participants to talk about their experiences.

-

Observation in the form of field notes

Field notes are notations generally made to document observations during an interview. According to Streubert and Carpenter (1999:26), field notes should indicate/express what researchers see, think or experience. In this study, the researcher recorded observational, theoretical, methodological and personal notes during the interviews (Wilson 1989 : 434-435). Data analysis ran concurrently with data collection.

\section{Data Analysis}

The data collected in the field notes and tape recordings were analyzed using Tesch's method (Cresswell, 1994: 155) Data were listed and grouped into preliminary groupings of descriptive themes agreed upon by the researcher and the supervisor as an expert in the field of research and quality improvement in health care. The researcher analyzed the data systematically step by step as follows:

- The researcher got a sense of the whole. Read through all transcription carefully. Ideas were jotted down as they came to mind.

- $\quad$ The researcher picked one document (one interview) from the top of the pile. The researcher went through it, asked himself, what it was about. Did not think about the "substance" of the information but rather its underlying meaning. Wrote down thoughts in the margin. Then the researcher clustered together 
of between four and fifteen employees, who work in the same or similar area of an organization and who meet voluntarily on a regular basis to identify, assess and solve problems in their area of work.

Perception: Those subjective experiences of objects or events that ordinarily result from stimulation of the receptor organs of the body. (Science and Technology Encyclopedia).

Public Hospital: means premises in which patients are received and lodged for the purpose of hospital treatment (Common Wealth Consolidated Acts). In this research this term further refers to a government funded hospital in which this study was undertaken.

\section{Research design and methods}

$A$ research design guides the researcher in planning and implementing the study in a way that is most likely to achieve the intended goal (Burns \& Grove 1997:225). In this study, the researcher used an explorative, descriptive and contextual qualitative research design.

\section{Population}

According to Polit \& Hungler (1995:230) and Wilson (1989:150) it is important, when identifying a population, to be specific about the criteria for inclusion in the population. The sampling criteria for this study were:

- $\quad$ they could be male or female, as the findings would be understood with reference to both sexes;

- they had to be professional nurses

- the ability to spcak Xhosa or English was a strong recommendation

- had a working experience of at least two years at this public hospital was required as this period guarantecd that the participants were acquainted with a quality circle programme. they had to have served in a quality circle in their clinical area they had to have one week's induction in quality circle management

- they had to give permission for the interviews to be taperecorded and field notes to be taken

\section{Sampling Technique}

For the purpose of this research, a purposive or judgemental (that is, nonprobability) sampling was used. The technique involves non-random sampling of informants that leads to nonrepresentative sampling of the population (Wilson 1989: 261). This sampling technique was chosen because it offered the researchers participants who had knowledge of quality circle programme in this public hospital.

In this study, the number of participants interviewed was not important, but the researcher collected data until saturated. The sample was drawn from a population of 425 professional nurses working in a public hospital of the Eastern Cape Province. The sample comprised eight professional nurses who volunteered for in-depth individual semi-structured interviews. According to Morse (1995:147), saturation of data is reflected by repeated themes with no new themes emerging. Although data saturation was reached in the fourth interview, the researcher continued with all the interviews and no new themes emerged.

\section{Data Gathering}

Data was gathered using two techniques: in-depth individual semi-structured interviews and observation in the form of field notes. These methods are described briefly below:

\section{- In-depth individual semi- structured interview}

Semi-structured interviews were used to collect data. According to Burns and Grove (1997:353), an interview involves verbal communication between the researcher and the respondent during which information is provided to the researcher.

The in-depth individual semi-structured interview encourages participants to converse freely about the research question(s). The researcher focused on issues of importance to the research question (Polit \& Hungler 1995: 272; Rose 1994: 24; Wilson 1989: 437). According to Rose (1994:24) semistructured interviews could yield valuable data if decisions are taken on who conducts the interview, where they should take place, and how information should be recorded, stored and analyzed. In this study, the researcher conducted in-depth semi-structured individual interviews with professional nurses who met the eligibility criteria. After initial contact with professional nurses selected according to the sampling criteria chosen for this research, informed consent was obtained to use a tape recorder. Date, time and place of interview were confirmed.

The interviews were conducted in a quiet place and the participants were made comfortable for the duration of the interview session. A tape recorder was used to capture the dialogue between the interviewer and the intervicwee. The following question was posed to all the interviewees: "How do you experience the implementation of the quality circle programme in this hospital?" Facilitative communication skills were employed to encourage participants to talk about their experiences.

\section{- Observation in the form of field} notes

Field notes are notations generally made to document observations during an interview. According to Streubert and Carpenter (1999:26), field notes should indicate/express what researchers see, think or experience. In this study, the researcher recorded observational, theoretical, methodological and personal notes during the interviews (Wilson 1989: 434-435). Data analysis ran concurrently with data collection.

\section{Data Analysis}

The data collected in the field notes and tape recordings were analyzed using Tesch's method (Cresswell, 1994: 155) Data were listed and grouped into preliminary groupings of descriptive themes agreed upon by the researcher and the supervisor as an expert in the field of research and quality improvement in health care. The rescarcher analyzed the data systematically step by step as follows:

- The researcher got a sense of the whole. Read through all transcription carefully. Ideas were jotted down as they came to mind.

The researcher picked one document (one interview) from the top of the pile. The researcher went through it, asked himself, what it was about. Did not think about the "substance" of the information but rather its underlying meaning. Wrote down thoughts in the margin. Then the researcher clustered together 
similar topics into columns arranged as major topics, unique topics and leftovers.

- $\quad$ The researcher took this list and went back to the data. He abbreviated the topics as codes and wrote the codes next to the appropriate general segments of the text. He tried a preliminary organizing scheme to see whether new categories and codes emerged.

- The researcher used descriptions for the topics and divided them into categories. Relating them to each other reduced the number of topics. Interrelationships were also indicated

- The researcher recoded the existing data. The researcher then undertook a literature review to compare the categories and findings.

\section{Literature Control}

According to Streubert and Carpenter (1999:20), it is important to conduct a literature review after analyzing the data. In qualitative research, the purpose of this is to place the findings in the context of what is already known. In this study, the literature review enabled the researcher to identify the similarities and differences between the present and previous studies as well as the potential contribution of this study (Streubert \& Carpenter, 1999:20). For results to be authentic, they must be trustworthy or valid.

\section{Trustworthiness of research findings}

Lincoln and Guba's (1985:290) model was used to ensure trustworthiness in this study. The model applies the criteria of truth value, applicability, consistency and neutrality. See following subheadings for the application of the model for trustworthiness in this study.

\section{Truth value (credibility)}

Truth value (credibility) establishes how confident the researcher is with the truth of the findings based on the research design, informants and context. According to Lincoln and Guba (1985:80), in qualitative research truth value is obtained from the discovery of human experiences as they are lived and perceived by the informants. In this study this is how credibility was achieved:

- $\quad$ Prolonged and varied field experience. The researcher experience of 22 years' in the facility where the study was conducted plus four months preparation for the fieldwork.

- Referential adequacy. The researcher applied a pilot interview that equipped him for the eventualities of the fieldwork. This pilot interview was discussed with two experts.

- Reflexivity. The researcher used a field journal to reflect his behaviour and experience.

- Triangulation. The researcher used in-depth individual semistructured interviews and field notes for data collection. The researcher also used triangulation of design, qualitative research, exploratory research, descriptive research and contextual design.

- Peer examination. The researcher was assisted by two experts in qualitative research to ensure that high standards of research were maintained throughout the study.

- Member checking. The researcher continuously checked information gathered with the informants to confirm it. The researcher conducted a literature review to link the findings with previous research. The researcher used a tape recorder to capture interviews verbatim.

- Authority of the researcher. The researcher underwent extensive training in conducting interviews to ensure the quality of the data.

- Structural coherence. The research process was conducted within Donabedian's (1980) model for evaluating health care services cited in (Bowling, 2002:9).

\section{Applicability}

Applicability refers to the degree to which the findings can be applied to other contexts and settings or with other groups (Lincoln \& Guba 1985:80). Sandelowski (1986:32) contends that generalisation is irrelevant in qualitative research as these studies are undertaken in naturalistic settings with few controlling variables. Lincoln and Guba (1985:81) use fittingness or transferability instead of generalisation as the criterion for the applicability of qualitative data. Lincoln and Guba (1985:81) go on to say that qualitative research meets this criterion when the findings fit into contexts outside the study situation, that are determined by the degree of similarity of goodness of fit between two contexts.

\section{Consistency}

According to Lincoln and Guba (1985:81), consistency refers to whether the findings would be consistent if the study were replicated with the same informants or in a similar context. The key to qualitative research is to learn from informants rather than to control them. In this study the researcher employed the following strategies to ensure consistency:

- Dependability audit. The researcher conducted in-depth semi-structured individual interviews, which were audio tape-recorded to ensure an audit trail. The researcher use Cresswell's method of data analysis that can be followed (trailed) step by step. A literature review verified the collected data.

- Dense description. Full method of data collection and analysis was explained.

- Triangulation. Triangulation was used in the same manner as for credibility.

- Peer examination. This strategy was used in the same manner as for credibility.

\section{Neutrality}

Lincoln and Guba (1985:82) shift the emphasis of neutrality in qualitative research from the researcher to the data. In other words, data neutrality but not investigator neutrality is the criterion of neutrality, and this can be achieved when truth value and applicability are established. In this study, the researcher employed the following strategies to ensure neutrality:

- Confirmability. An expert was selected to audit and look at the standards of the research.

- Triangulation. Was used in the same manner as for credibility. 
Reflexibility. The researcher kept a field journal of his behaviour and experiences by jotting down his observation during the interviews as field notes.

\section{Research findings}

As indicated earlier (in the abstract), there was only one theme identified, namely: the nurses' perception of quality circle as a forum for discussing and planning quality patient care. This means that the professional nurses regard a quality circle programme as a forum that brings them closer to each other; that is, they emerge as a team that has a common goal of sustaining continuous quality improvement. This team ensures that team members are empowered so that problems that ensue from nursing practice are solved effectively and thereby maintain high quality patient care standards.

According to the Quality Circle Forum of India (QCFI) (1999:1), a quality circle is a forum for solving departmental problems, using A, B, C classification. This classification means that a list of problems for a department is generated through a brainstorming session in a quality circle and problems are classified. Category A problems have minimum involvement of other departments in solving them; category B problems necessarily require the involvement of other departments, and category $\mathrm{C}$ problems need management sanction and support. Ovretveit et al (2002:345-351) maintain that collaborative teams stimulate improvements in patient care and organisational performance. The theme had four categories namely, staff empowerment; team building in nursing, maintenance of standards by nurses and challenges to sustaining continuous quality improvement.

\section{Staff Empowerment}

A quality circle is a forum that brings departmental staff together and crosspollination of ideas, skills and information occurs among them. Increased staff interaction leads to decision-making at departmental level, which is an indication of increased empowerment. In this study, the nurses understood empowerment as: "Quality circles consist of individuals from each individual place to solve a particular problem and their skills and knowledge make them the likely source of solutions. Our professionals need to develop and sharpen their skills, their knowledge."

Naude (1997:34) defines empowerment as a process that occurs when the traditional hierarchy starts to fade or falls away and the need arises for the employees to take responsibility for the success of the organisation. Naude asserts that empowerment is a process that should be harnessed by leaders who should increase their self-awareness and empower the followers to utilise their unique knowledge, skills, experience and creativity in the support of the process. Apps (1994:147) maintains that the process of empowering is both giving power (power sharing) and acknowledging the power that already exists in people.

Fullam, Lando, Johansen, Reyes and Szaloczy (1998:255) state that empowerment depends on the symbiotic relationship of nurse, environment, and leadership style. According to them, nurses' professional traits are like fertile ground waiting to be cultivated, the environment must support nurses through their professional growth and patient care, and leadership style nurtures nurses towards empowerment. Jooste and Booyens (1998:24) indicate that empowerment means more than merely giving consent to nurses to exercise control over their management tasks, but also refers to the use of people's potential and competencies, the discovery of new expertise and the creation of new opportunities to apply such competencies. Individuals who are physically, emotionally and psychologically independent are ready to serve in a team.

\section{Team building in nursing}

The quality circle programme became a catalyst for the staff of a department to act together as a team. Before the implementation of the programme, they did not have the common goal necessary to transform into a team. The function of the steering committee is to enable the group to have and achieve a common goal. Each quality circle has a steering committee. The steering committee is representative of all the nursing units in that quality circle in order to facilitate effective communication. The steering committee ensures that quality circle meetings are held weekly, that everybody participates in the discussions, that decisions taken are implemented and monitored and that timely feedback is given to the quality circle. This is what the respondents had to say:

"Quality circles are for everybody; all categories are included. The chairperson should be a responsible, diligent and committed person with good communication and leadership skills."

Bateman (1997:1) defines team building as an effort in which a team studies its own process of working together and acts to create a climate that encourages and values the contributions of team members. Bateman (2002:1) adds further that team building is the process of enabling that group of people to reach their goal. Bateman notes that team building is about creating courteous behaviours, improving communication, becoming better able to perform work tasks together, and building strong relationships. The data analysis revealed four sub-categories of team building, namely: 1) Roles and responsibilities of the steering committee/team leader; 2) Improved interpersonal relationships; 3 ) Improved intradepartmental relations; 4) Improved problem-solving skills.

\section{Roles and responsibilities of the team leader}

The quality circle members regarded the team leader as the pivot of the steering committee and the quality circle programme. The leader of the steering committee is responsible for the strategic planning for each department, which culminates in a vision, a mission statement, objectives and the action plans for the department and strengths, weaknesses, opportunities and threats (SWOT) analysis for the department. Gunden and Crissman (1992:7) point out that leaders in organisations have a responsibility to bring out the best in those they serve by acknowledging that the person doing the job knows better than anyone else how to improve it. The data analysis revealed two more subcategories: values of the chairperson and attributes of the chairperson of the steering committee. With regard to the chairperson's role, the respondents stated that "the team leader should be able to plan in advance, implement, monitor and evaluate the programme".

Gunden and Crissman (1992:6-7) declare that it is the leader's responsibility to set the stage for transformation by eliminating disempowering behaviours like controlling and domineering 
leadership styles. They add further that a leader's empowering behaviours, such as enabling others to act, teaching, coaching and role modeling the way, and inspiring a shared vision, promote creativity and autonomy in decisionmaking among staff (Gunden \& Crissman 1992:8).

\section{- Values of the steering committee chairperson}

The respondents identified credibility, competence, and good judgement in decision making as values of the person who is to lead them:

"The chairperson should be a responsible, diligent, committed person with good communication and leadership skills. The other people in the quality circle should own it, claim it, and should have the same aims. Everybody should have one common aim, that is, the uplifiment of our. department."

Gunden and Crissman (1992:8) maintain that leaders should lead and manage themselves effectively before leading others. In addition, followers want their leaders to be honest, competent, forward looking, and inspiring.

\section{- $\quad$ Attributes of the steering committee chairperson}

The respondents indicated that the chairperson should have leadership skills, especially transformational leadership skills, and be creative, interactive, empowering, visionary, and passionate about nursing:

"The leader, for example, is supposed to initiate and facilitate the meetings, encourage team members to speak their minds. The team leader should work hand in hand with a quality assurarce coordinator".

Hackman and Johnson (1996:92-96) identify five attributes of transformational leaders: they are highly creative, effective communicators, visionaries, empowering, and passionate about their work. Flarey (1996:189-190) identifies four crucial leadership features of facilitating quality improvement programmes, namely visioning, empowerment, communication and commitment. Nazarey (1993:10) holds that the leader must coax staff to be active participants in designing their own development.

\section{Improved interpersonal relations}

Before the implementation of the quality circle programme, the nurses were content to stay in their nursing units, not interacting with the other nurses in their department. After the implementation of the quality circle programme, the nurses used the quality circle as the forum for interacting meaningfully. They became aware of their goal and their role of uplifting the standards of their departments. This is what they had to say:

"The quality circles were introduced as a tool for members of the whole department to meet. Sources of conflict could be a lack of good relations amongst service providers. The meetings are held weekly. Doctors also do attend though not frequently."

Bateman (2002:2) points out that people cannot work together if they are not clear about the terms of reference. He identifies four central issues that keep people talking in the team, namely, goal, role, procedural and interpersonal issues. Bateman (2002:3) goes on to say that the extent to which people feel comfortable with each other beyond the facilitation meetings does influence the effectiveness of the team. Lurie, Merrens, Lee and Splaine (2002:825-845) state that communication is the cornerstone of effectiveness of multidisciplinary teams in quality improvement in health services. Good interpersonal relationships are the foundation of good intradepartmental relations.

\section{Improved intradepartmental relations}

Besides interpersonal relations, the participants also referred to intradepartmental relations or communication amongst the nursing units that constitute a department. This communication was minimal before the implementation of a quality circle programme, leading to a lack of cooperation amongst the units and poor patient care. Both material and human resources were not managed efficiently. The participants regard a quality circle as a forum that brings these units closer thus improving utilisation of resources and conflict management:

"Before the implementation of the quality circle programme, nursing units of the same department found it very hard to sort out their problems, and as such there was so much conflict between units of the same department. Each nursing unit works on its own."
With regard to interpersonal relations, Bateman (2002:1) states that a group becomes a team when the individual members are sure enough of themselves and their contribution to praise the skills of others and, furthermore, the team values the fact that whatever they achieve they do together. According to Bateman (2002:2), a common goal is a unifying force in any team and role clarification among the members is a factor in minimising conflicts in a team. Good interpersonal and intradepartmental relations therefore form the foundation for good management of problems.

\section{Improved problem-solving}

Problem solving is characterised by the technique of brainstorming to generate and classify a list of problems as A, B, C and so on. Category $A$ problems includes minimum involvement of other departments in solving them; category $B$ problems of necessity involve other departments, and category $\mathrm{C}$ problems may require management sanction and support in implementing the solution (QCFI 1999:1).

The implementation of quality circles provided a forum for discussing problems within the department. At the quality circle meetings, interpersonal, interdepartmental and intradepartmental problems are tackled. The steering committee represents all the nursing units so all the nursing units are involved in problem-solving. The common goal of the quality circle, namely the provision of quality patient care, has a unifying effect.

Nursing units of the same department find it very hard to solve their own problems by themselves. There is a feeling of belonging in these people. People become very vocal with a good attitude then collective partnerships develop.

\section{Maintenance of standards by nurses}

Before the implementation of the quality circle programme, problems and conflicts were solved in isolation therefore everybody did not own the standards set. Once a quality circle programme had been implemented departments use quality circles as a forum for solving problems and reviewing standards. Setting standards involves three steps: setting, monitoring and revisiting (reviewing and, 
if necessary, revising) standards. In a quality circle, people are empowered and work in teams thereby creating an environment conducive to standard setting and maintenance. These standards are monitored by mechanisms like nursing auditing decided on in the quality circle.

There are hospital standards but as a department we felt the need to make our own stanclards and if it happens that a standard is not met, that one is discussed with the persons involved in the quality circle. If, when a standard was set, there were loopholes, these must be corrected. and it means that the standard is revisited.

In regard to the pivotal role of standards in any profession, Searle and Pera (1995:122) state that professional recognition in nursing has its roots in many factors, particularly professional solidarity, competence, accountability and strict adherence to a professional code of ethics with the public weal as the primary concern.

Mellish and Brink (1990:42-45) point out that the National Department of I lealth is responsible for the coordination and provision of additional health necessities for a comprehensive health service for South Africa. This implies that normative standards should be made available to health care professionals. Bowling (2002:8) contends that reviewing and monitoring current practice can only be done against the predefined standards.

Challenges to sustaining quality circles The implementation of the quality circle programme challenged and changed the way of doing things and initially the nurses were apprehensive.

\section{Staff attitudes}

Some of the respondents regard the quality circle programme as bringing too much work and a waste of time. Some maintain it is ill timed because with the serious shortage of staff there is no time to attend the meetings. According to the respondents:

"The quality assurance department was taken for granted probably due to ignorance. Some complain about shortage of staff. thinking that the programme was a waste of time and such that we still experience problems in coping in all the quality circles."

Moreo (1996:11) observes that $68 \%$ of customers just switch to the competitor because of the attitude of the personnel. Moreover, attitudes are not innate traits of individuals, but the product of conditioning people's minds either by others or themselves. This implies that attitudes can be manipulated either by co-workers or leaders or managers (Moreo 1996:12).

\section{Election of steering committee}

There was a strong feeling amongst the respondents that the election of the steering committee threatens the existence of quality circles because sometimes the chairperson has no leadership quality but was elected on the basis of popularity:

"I would like to improve the election of the steering committee; sometimes people just elect popular people without looking at leadership atributes."

Snow and orlikoff(1984:37) found that in several hospitals in the usa, the steering committees were composed of administrators and middle managers, all of whom were selected because of their commitment to participative management.

\section{Staff shortage}

Another problem was the shortage of staff in the hospital where the study was conducted. The participants responded as follows on this issue:

"Hindrances we are experiencing so far are a shortage of staff, shortage of equipment, shortage of skilled personnel. Doctors do not adequately attend quality circles as would be preferable because of time constraints."

\section{Attending quality circle meetings}

It became clear that holding quality circle meetings was a major problem in other departments. This might have been due to the fact that the people who were in charge of the quality circles did not consult with other staff members before planning the dates and times of meetings.

The days and time of holding the meetings are very important so that people do not choose days that are busy in the department, such as operation days, major doctors' rounds, when we need more staff in the ward and therefore people will not be able to attend the quality circle.

\section{Loss of focus during quality circle meetings}

There was a tendency for some of the quality circle meetings to lose focus due to staff members who shifted focus from patient issues to their personal issues. The people in our departments have a tendency to change the aim of the quality circles and they want to involve their social issues rather than the patient care.

\section{Limitations of the study}

This study involved only the xhosaspeaking professional nurses of a single public hospital. This means the findings of the study are understood within a certain context, that is, professional nurses of the eastern cape province who belong to the ethnic group of the xhosas. The sub-professional categories were not included hence their perception of the implementation of the programme was not included.

\section{Recommendations}

Based on this study and its findings, the researcher makes the following recommendations for nursing practice, nursing education, and further nursing research.

\section{Nursing practice}

In this study, quality circles are perceived as a forum for discussing and planning quality patient care. To improve the interpersonal, intradepartmental and interdepartmental communication in nursing service management, it is recommended that the three tiers of nursing management be involved in the quality circle programme. Nursing practice is then likely to improve as quality circles depend on evidence-based practice, which is characterised by constant improvement of services and products (MacPhee 2002:450-454).

\section{Nursing education}

The researcher is of the opinion that continuous quality improvement should constitute an integral aspect of the nursing curriculum so that nurses become conversant with quality management concepts at an carly stage of their professional lives. Nursing education could utilise the quality circle programme as this forum would give the nurse educators and student nurses an opportunity for rapport that is crucial in any teamwork.

\section{Nursing research}

It is recommended that further research be conducted into: 
the implementation of quality circles, involving professional nurses of other ethnic groups in other public hospitals

quantifying the findings of this study to determine whether these views are generalisable within the public hospital where the project was conducted.

\section{Conclusion}

This research revealed that a bottom-up approach to quality improvement is necessary in solving nursing staff problems in a public hospital as evidenced by the use of quality circle programme. It is clear that quality circles have the potential to include staff in problem solving for improved patient care.

\section{Bibliography}

APPS, JW 1994. Leadership for the emerging age, transforming practice in adult and continuing education. San Francisco: Jossey-bass.

BATEMAN, A 1997. Developing a productive team. Teambuilding. www.ianr.unl.edu/pubs/misc/ cc352.htm

BATEMAN, A 2002. Developing a productive team. Teambuilding. www.ianr.unl.edu/pubs/misc.

BOWLING, A 2002. Research methods in health: investigating health and health services. Second edition. Philadelphia: Open University Press.

BURNS, N \& GROVE, SK 1997. The practice of nursing research: conduct, critique and utilization. Third edition. Philadelphia: Saunders.

COLIINS ENGLISH DICTIONARY. 1991 Third edition. Glasgow: Harper Collins.

COMMON WEALTH CONSOLIDATED ACTS. NATIONAL HEALTH ACT 1953 - SECT 84. http:// www.austlii.edu.au/au/legis/cth/ consol_a ct/nhal953147/ s84.html\#hospital

CRESSWELL, JW 1994. Research design: qualitative and quantitative approaches. London: Sage.

DONABEDIAN, A 1980. The definition of quality and approaches to its assessment. Volume 1. New York: Health Administration Press.

FLAREY, DL 1996. Quality leadership: involving staff in continuous quality improvement. Seminars for Nurse Managers, 4(4): 187-190.

FULLAM,C; LANDO, AR; JOHANSEN, REYES, A \& SZALOCZY, DM 1998. The triad of empowerment: leadership, environment and professional traits. Nursing Economics, 16(5):254-257.

GILLIES, AN 1997. Improving the quality of patient care. Essex: Longman.

GUNDEN, E \& CRISSMAN, S 1992. Leadership skills for empowerment. Nursing Administration Quarterly, 16(3):6-10

HACKMAN, HZ \& JOHNSON, CE 1996. Leadership: a communication perspective. Second edition. Waveland: Prospect Heights.

JOHNSSON, C; CARLSSON, R \& LAGERSTROM, M 2002. Evaluation of training in patient handling and moving skills among hospital and home care personnel. Ergonomics, 45(12):850-865.

JOOSTE, D \& BOOYENS, S 1998. Guidelines for the empowerment of nurses in health services. Health SA Gesondheid, 3(3):24-30.

LINCOLN, YS \& GUBA, EG 1985. Naturalistic inquiry. Newbury Park, CA: Sage.

LURIE, JD; MERRENS, EJ; LEE, J \& SPLAINE, ME 2002. An approach to hospital quality improvement. Med-ClinNorth-Am 86(4):825-845.

MACPHEE, M 2002. Using evidencebased practice to create a venous access team: The venous access task force of the children's hospital of Denver. Journal for Paediatric Nursing 17(6):450-454.

\section{MCLAUGHLIN, CP \& KALUZNY, DD} 1999. Continuous quality improvement in health care: theory, implementation and applications. Second edition. Maryland: Aspen.

MELLISH,JM \& BRINK, H 1990. Teaching the practice of nursing: a text in nursing didactics. Third edition. Durban: Butterworths.
MOREO, J 1996. Delivering an exceptional customer service: a handbook for the person working at Frontline. Pretoria: Knowledge Resources.

MORSE, JM 1995. Nursing research: the application of qualitative approaches. London: Chapman \& Hall.

MULLER, ME 2000. The quality of nursing service management in South African hospitals: review article. Curationis 23(2):63-69.

NAUDE, M 1997. Empowerment through effective leadership by nursing unit managers. Nursing News, June:34-36.

NAZAREY, P 1993. The spirit of nurse empowerment: a leader's responsibility. Emphasis: Nursing 4(2):7-12.

NZANIRA, DG 2002. Transforming health service delivery through quality improvement and accreditation. Service Delivery Review 1(3):9-13.

OVRETVEIT, J; BATE, P; CLEARY, P; CRETIN, S; GUSTAFSON, D; MCINNES, K; MCLEOD, H; MOLFENTER, T; PLSEK, P; ROBERT, G; SHORTELL, S \& WILSON, T 2002. Quality collaborative: lessons from research. Qual-Saf-Health-Care 11(4):345351.

POLIT, DF \& HUNGLER BP 1995. Nursing research: principles and methods. Fifth edition. Philadelphia: Lippincott.

QCFI - see Quality Circle Forum of India.

QUALITY CIRCLE FORUMOF INDIA. 1999. What are quality circles? Page 1-4. Internet Explorer Ó 4.0(+).

ROSE, K 1994. Interviewing techniques: unstructured and semi-structured interviewing. Nurse Researcher 1(3):2331.

SANDELOWSKI, M 1986. The problems of rigor in qualitative research. Advances in Nursing Science 8(3):27-37.

SCIENCE AND TECHNOLOGY ENCYCLOPEDIA: The meaning of perception. McGraw Hill Publishers. http://www.answers.com/topic/ perception

SEARLE, C \& PERA, SA 1995. 
Professional Practice: A Southern African Nursing Perspective. Third Edition. Durban: Butterworths.

SNOW, N \& ORLIKOFF, SE 1984. Quality circles as a management tool. Chicago: Mosby.

STREUBERT, HJ \& CARPENTER, DR 1999. Qualitative research in nursing. Philadelphia: Lippincott.

WEEKS, WB 2002. Quality improvement as an investment. QualManag-Health-Care 103):55-64.

WILSON, HS 1989. Research in nursing. Second edition. New York: AddisonWesley. 